\title{
Phorbol Myristate Acetate Inhibits the Bradykinin-Induced L-Nitro-Arginine Insensitive Endothelium-Dependent Relaxation of Bovine Coronary Artery
}

\author{
Takeshi Obi, Fumio Suzuki and Akira Nishio* \\ Department of Veterinary Pharmacology, Faculty of Agriculture, Kagoshima University, Kagoshima 890, Japan \\ Received May 27, 1993 Accepted August 23, 1993
}

\begin{abstract}
The effects of L-nitro-arginine (LNAG) and phorbol myristate acetate (PMA) were studied in bradykinin-induced relaxations in bovine coronary arteries. In the presence of indomethacin $(10 \mu \mathrm{M})$, neither LNAG $(100 \mu \mathrm{M})$ nor PMA $(0.1 \mu \mathrm{M})$ inhibited the bradykinin-induced relaxations in coronary arterial rings contracted with prostaglandin $F_{2 x}$. However, simultaneous application of LNAG and PMA almost completely abolished the bradykinin-induced relaxation. In a sandwich-method, endothelium-intact coronary arteries (donor vessels) were treated with LNAG or with PMA for $30 \mathrm{~min}$ and then placed in close apposition to a denuded ring (assay vessel). Pretreatment of the donor vessels with LNAG, but not with PMA, almost completely abolished the bradykinin-induced relaxations in the assay vessel. In contrast, treatment of the assay vessel with PMA or with LNAG had no effect. These results suggest that bradykinin-induced endothelium-dependent relaxation of bovine coronary artery depends on both the release of nitric oxide and other endothelium-derived relaxing factor(s), which is an extremely labile substance(s), or a nondiffusible factor(s). PMA seems to inhibit the production and/or the release of the latter substance(s).
\end{abstract}

Keywords: Endothelium-dependent relaxation (bradykinin-induced), Coronary artery (bovine), L-Nitro-arginine, Nitric oxide, Phorbol myristate acetate

It has been shown that bradykinin induces endothelium-dependent relaxation of arteries isolated from a variety of species by releasing endothelium-derived relaxing factors (EDRFs) (1). It has been reported that one of the EDRFs is nitric oxide or a labile nitric oxide-containing substance $(2,3)$. However, recent studies indicated that nitric oxide does not account for all of the endothelium-dependent relaxations evoked by bradykinin $(4,5)$. In addition, bradykinin has been shown to induce endothelium-dependent hyperpolarization of porcine coronary arteries, which is probably due to the release of endothelium-derived hyperpolarizing factor (EDHF) (6-8).

In porcine coronary arteries, it has also been reported that nitric oxide probably does not play a major role in the bradykinin-induced endothelium-dependent relaxation $(9,10)$. Recently, we have also found that bradykinin evokes the endothelium-dependent relaxations in the presence of indomethacin and L-nitro-arginine (LNAG) in bovine coronary arteries (11).

\footnotetext{
* To whom correspondence should be addressed.
}

In the present study, we determined if bovine coronary arteries release EDRFs other than nitric oxide in response to bradykinin using a sandwich-bioassay system. We also examined the effect of phorbol esters on the bradykinininduced relaxation, because phorbol esters have been shown to inhibit the release of EDRFs $(12,13)$.

\section{MATERIALS AND METHODS}

Experiments were performed on left circumflex coronary arteries isolated from bovine hearts obtained from a nearby slaughterhouse. Coronary arteries were carefully dissected and cleaned of adhering connective tissue.

In the organ chamber experiment, the left circumflex coronary arteries were cut into $3-$ to $4-\mathrm{mm}$ rings and mounted horizontally in organ chambers filled with $15 \mathrm{ml}$ of Krebs-Ringer bicarbonate solution of the following composition: $118 \mathrm{mM} \mathrm{NaCl}, 4.7 \mathrm{mM} \mathrm{KCl}, 1.2 \mathrm{mM} \mathrm{MgCl}_{2}$, $1.2 \mathrm{mM} \mathrm{KH}_{2} \mathrm{PO}_{4}, 2.5 \mathrm{mM} \mathrm{CaCl}_{2}, 25 \mathrm{mM} \mathrm{NaHCO}_{3}$ and $10 \mathrm{mM}$ glucose. The chamber solution was maintained at $37^{\circ} \mathrm{C}$ and gassed with $95 \% \mathrm{O}_{2}$ and $5 \% \mathrm{CO}_{2}$. The coronary 


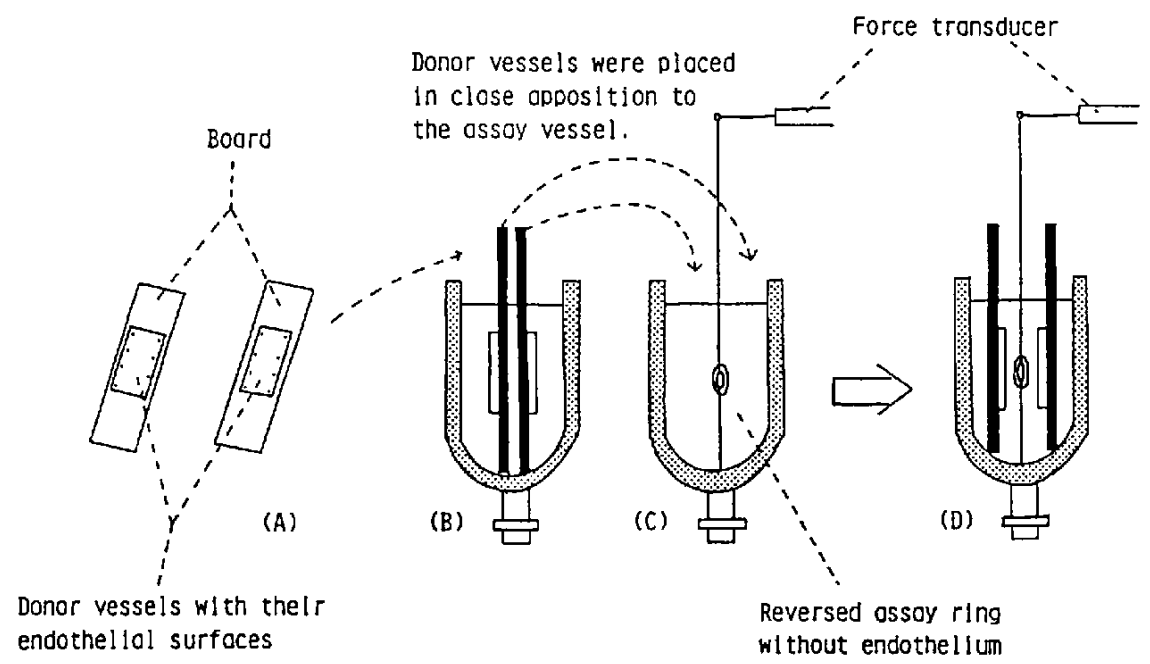

Fig. 1. Sandwich method for bioassay of endothelium-derived relaxing factor(s). The endothelium-intact vessels (donor vessels) isolated from a bovine coronary artery were attached to boards (A) and equilibrated in an organ chamber for $120 \mathrm{~min}$ (B). A reversed ring (assay ring) without endothelium, isolated from the same bovine coronary artery, was equilibrated in an another organ chamber $(C)$. After an assay ring was contracted with prostaglandin $F_{2 c}\left(3 \times 10{ }^{6} \mathrm{M}\right)$, donor vessels were transferred into the assay chamber (D).

rings were attached to a force transducer, and isometric force was recorded. Each coronary ring was stretched to an optimal tension of $20 \mathrm{mN}$, as determined by repeated stimulation with $60 \mathrm{mM} \mathrm{KCl}$. They were allowed to equilibrate for $90-120 \mathrm{~min}$ before starting the experiments.

In the bioassay experiment, two segments with endothelium were obtained from a circumflex coronary artery. They were cut into 9- to 10-mm rings and then opened. The opened circumflex coronary arteries (donor vessels) were fixed on a plastic board, as shown in Fig. 1. To detect released EDRFs from the donor vessels, a reversed ring of de-endothelialized left circumflex coronary artery (assay ring) was mounted in an organ chamber and contracted with prostaglandin $\mathrm{F}_{2 \alpha}\left(\mathrm{PGF}_{2 \alpha}\right)\left(3 \times 10^{-6}\right.$ $\mathrm{M})$. The isometric tension of the assay ring was measured by a force transducer. Donor vessels were transferred to the assay chamber, and then basal and bradykinin-induced release of EDRF from donor vessels was determined.

All experiments were performed in the presence of indomethacin $\left(10^{-5} \mathrm{M}\right)$ to eliminate the effects of prostanoids (14).

The following drugs were used: bradykinin, LNAG, phorbol 12-myristate-13-acetate (PMA), 4-alpha-phorbol 12,13-didecanoate ( $4 \alpha-\mathrm{PDD})$, hemoglobin and $\mathrm{D}$-arginine hydrochloride (Sigma Chemical Company, St. Louis, MO, USA); indomethacin, methylene blue and sodium nitroprusside (Nacalai Tesque, Inc., Kyoto); $\mathrm{PGF}_{2 \alpha}$ (Ono Pharmaceutical Co., Ltd., Osaka); L-arginine hydrochloride (Wako Pure Chemical Industries, Ltd., Inc., Osaka).
PMA and $4 \alpha$-PDD were dissolved in dimethylsulfoxide (final bath concentration of less than $0.1 \%$ ). Oxyhemoglobin was prepared by adding a 10 -fold excess of the reducing agent sodium dithionite to a $10^{-3} \mathrm{M}$ solution of commercial hemoglobin in distilled water. Sodium dithionite was then removed by dialysis five times against 100 volumes of distilled water for $4 \mathrm{hr}$ at $4^{\circ} \mathrm{C}$. Other drugs were dissolved in distilled water. The drugs were kept on ice during the experiments. Concentrations of the drugs are expressed as the final organ chamber concentrations (molar).

Results are expressed as means \pm S.E.M. In rings contracted with $\mathrm{PGF}_{2 \alpha}$, responses are expressed as a percentage of the relaxation induced by $10^{-4} \mathrm{M}$ papaverine. Unless stated otherwise, $\mathbf{n}$ refers to the number of animals. Statistical evaluation of the data was performed by Student's $t$-test for either paired or unpaired observations. When more than two mean values were compared, analysis of variance was used. If a significant $F$ value was found, Scheffé's test for multiple comparisons was used to identify differences among groups. Values were considered to be statistically different when $P$ was less than 0.05 . The negative logarithm of the molar concentration of bradykinin causing $50 \%$ relaxation $\left(\mathrm{EC}_{50}\right)$ was calculated for each concentration-response curve, and the mean \pm S.E.M. of these values was presented.

\section{RESULTS}

Bradykinin evoked concentration-dependent relaxation in bovine coronary artery rings contracted with $\mathrm{PGF}_{2 \alpha}$. 


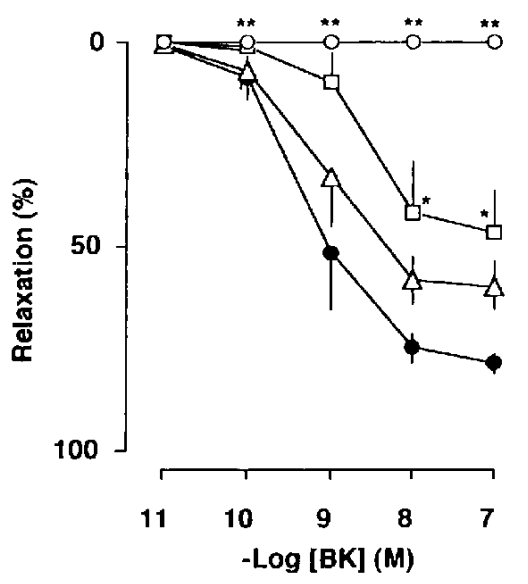

Fig. 2. Effects of endothelium-denudation, oxyhemoglobin $\left(10^{-5} \mathrm{M}\right)$ and methylene blue $\left(10^{-5} \mathrm{M}\right)$ on bradykinin (BK)-induced relaxation in bovine coronary arteries. Coronary rings were contracted with $\mathrm{PGF}_{2, \mathrm{x}}\left(3 \times 10^{-6} \mathrm{M}\right)$; the absolute contractions in controls (O), endothelium-denuded rings $(\bigcirc)$, oxyhemoglobin $(\triangle)$ - and methylene blue $(\square)$-treated rings were $43.3 \pm 3.9 \mathrm{mN} ; 48.9 \pm 2.8 \mathrm{mN}$; $56.6 \pm 3.4 \mathrm{mN}$; and $54.0 \pm 2.2 \mathrm{mN}$, respectively. Relaxations induced by papaverine $\left(10^{-4} \mathrm{M}\right)$ were taken as $100 \%$. Each point represents the mean \pm S.E.M. of five muscle strips from different animals. Endothelium-denudation and methylene blue inhibited the relaxations induced by BK significantly $\left({ }^{*} \mathrm{P}<0.05,{ }^{* *} \mathrm{P}<0.01\right)$.

As shown in Fig. 2, bradykinin-induced relaxations were not observed in de-endothelialized coronary rings, and they were little affected by oxyhemoglobin $\left(10^{-5} \mathrm{M}\right)$, but were significantly $(\mathrm{P}<0.05)$ inhibited by methylene blue $\left(10^{-5} \mathrm{M}\right)$; however, relaxations were still present at about $60 \%$ of the maximal ones.

Four left circumflex coronary rings isolated from the same bovine heart were used in the next experiment. As shown in Fig. 3A, bradykinin $\left(10^{-10}-10^{-7} \mathrm{M}\right)$ evoked concentration-dependent relaxation of an intact bovine coronary ring contracted with $\mathrm{PGF}_{2 \alpha}\left(3 \times 10^{-6} \mathrm{M}\right)$. Treatment of the coronary rings with LNAG $\left(10^{-4} \mathrm{M}\right)$ or PMA $\left(10^{-7} \mathrm{M}\right)$ had little effect on the endothelium-dependent relaxation induced by bradykinin (Fig. 3, B and C). Simultaneous application of LNAG and PMA almost completely abolished the bradykinin-induced endothelium-dependent relaxation in a coronary ring contracted with $\mathrm{PGF}_{2 a}$ (Fig. 3D). Results of the experiments are quantitatively summarized in Fig. 4. $\mathrm{EC}_{50}$ values for bradykinin were $(1.15 \pm 0.15) \times 10^{-9} \mathrm{M}$ in the control, $(1.71 \pm 0.16) \times 10^{-9}$ $M$ in the presence of LNAG $\left(10^{-4} \mathrm{M}\right)$, and $(1.83$ $\pm 0.19) \times 10^{-9} \mathrm{M}$ in the presence of PMA $\left(10^{-7} \mathrm{M}\right)$. There were no significant differences among these values. The maximal endothelium-dependent relaxation evoked by bradykinin was $69.5 \pm 5.4 \%$ in the control, $59.7 \pm 6.2 \%$ in the presence of LNAG and $70.7 \pm 5.3 \%$ in the presence of PMA. However, the maximal relaxation in the presence of both LNAG and PMA was $15.7 \pm 2.8 \%$, which was sig-

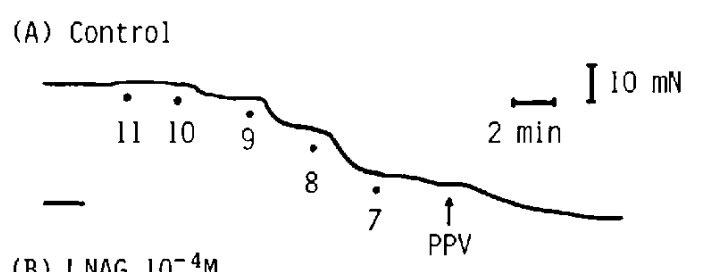

(B) LNAG, $10^{-4} \mathrm{M}$

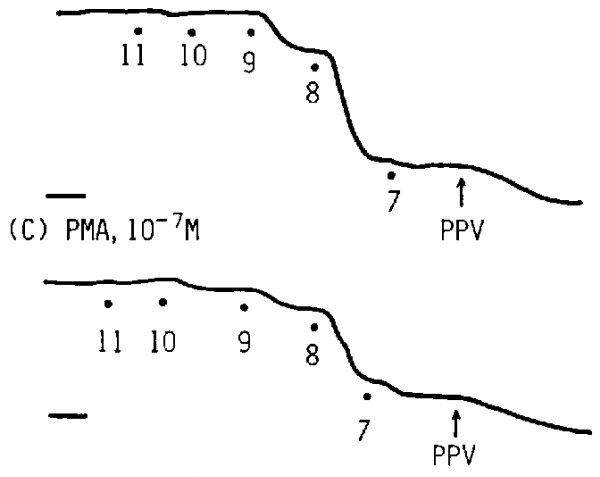

(D) $L N A G, 10^{-4} M+P M A 10^{-7} M$

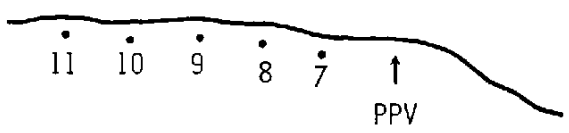

Fig. 3. Representative illustrations showing effects of L-nitroarginine (LNAG) $\left(10^{4} \mathrm{M}\right)$ and/or phorbol 12-myristate-13-acetate (PMA) $\left(10^{-7} \mathrm{M}\right)$ on bradykinin (BK)-induced endothelium-dependent relaxation in left circumflex coronary rings isolated from the same heart. Each coronary ring was contracted with prostaglandin $\mathrm{F}_{2 \alpha}\left(\mathrm{PGF}_{2 \alpha}\right)\left(3 \times 10^{-6} \mathrm{M}\right)$; horizontal lines represent the level before the addition of $\mathrm{PGF}_{2 \alpha}$. LNAG and/or PMA were present in the organ chamber $30 \mathrm{~min}$ before and during $\mathrm{BK}$ administrations. BK was added to the organ chamber at the points indicated; numbers indicate the concentration $(-\log \mathbf{M})$ of BK. PPV: papaverine $\left(10^{-4} \mathrm{M}\right)$.

nificantly smaller than the other values.

Concentration-dependent effects of PMA on the bradykinin-induced endothelium-dependent relaxation and the bradykinin-induced LNAG-insensitive, endothelium-dependent relaxation are shown in Fig. 5 ( $\mathrm{A}$ and $\mathrm{B}$ ). At a higher concentration $\left(10^{-6} \mathrm{M}\right)$, PMA depressed $10^{-9} \mathrm{M}$ and $10^{-8} \mathrm{M}$ bradykinin-induced endothelium-dependent relaxations (Fig. 5A). On the other hand, at relatively lower concentrations $\left(10^{-8}-10^{-7} \mathrm{M}\right)$, PMA inhibited the bradykinin-induced LNAG-insensitive, endothelium-dependent relaxation concentration-dependently (Fig. 5B). The inhibitory effect of a higher concentration $\left(10^{-6} \mathrm{M}\right)$ of PMA was not different from that of $10^{-7} \mathrm{M}$ PMA (Fig. 5B). In contrast to PMA, $4 \alpha-\mathrm{PDD}\left(10^{-7} \mathrm{M}\right.$ and $10^{-6} \mathrm{M}$ ) did not affect the LNAG-insensitive, endothelium-dependent relaxation evoked by bradykinin (Fig. 5C). PMA $\left(10^{-7} \mathrm{M}\right)$ showed no significant effects on the basal tension and $\mathrm{PGF}_{2 \alpha}$-induced contraction in 


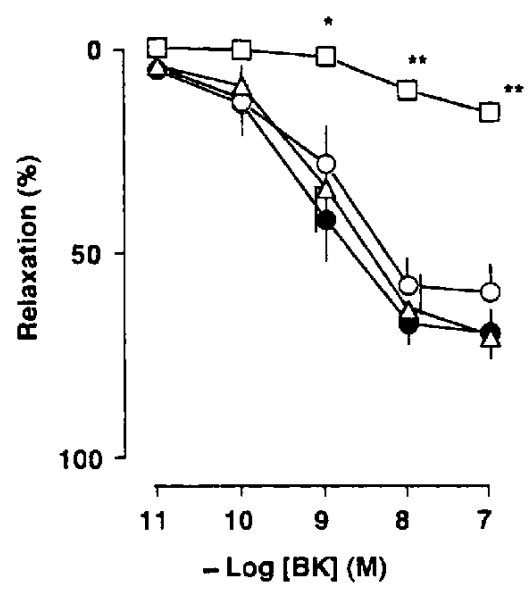

Fig. 4. Effects of L-nitro-arginine (LNAG) $\left(10^{-4} \mathrm{M}\right)$ and/or phorbol 12-myristate-13-acetate (PMA) $\left(10^{-7} \mathrm{M}\right)$ on bradykinin (BK)induced endothelium-dependent relaxation in bovine coronary arteries. Coronary rings were contracted with prostaglandin $F_{2 x}$ $\left(3 \times 10^{-6} \mathrm{M}\right)$; the absolute contractions in controls $(O)$, LNAG $(O)$-, PMA $(\triangle)$-, and their combined $(\square)$-treated rings were $47.6 \pm 3.2$ $\mathrm{mN} ; 55.0 \pm 3.7 \mathrm{mN} ; 52.9 \pm 2.8 \mathrm{mN}$; and $51.2 \pm 4.0 \mathrm{mN}$, respectively. Relaxations induced by papaverine $\left(10^{-4} \mathrm{M}\right)$ were taken as $100 \%$. Each point represents the mean \pm S.E.M. of nine muscle strips from different animals. Combination of LNAG and PMA inhibited the relaxations induced by BK significantly $\left({ }^{*} \mathrm{P}<0.05,{ }^{* *} \mathrm{P}<0.01\right)$.

endothelium-intact rings (data not shown) and on the nitroprusside-induced relaxations in de-endothelialized rings. $\mathrm{EC}_{50}$ values for nitroprusside in the relaxation were $(3.55 \pm 0.29) \times 10^{-9} \mathrm{M}$ in the control and $(4.47 \pm 0.31) \times$ $10^{-9} \mathrm{M}$ in the presence of PMA $\left(10^{-7} \mathrm{M}\right)(n=6)$. There was no significant difference between these two values.

Both basal and bradykinin-induced releases of relaxing factor(s) were examined using sandwich preparations. As shown in Fig. 6A, transfer of donor vessels to the assay chamber resulted in a small relaxation which may be due to basal release of relaxing factor(s) from donor vessels. Addition of bradykinin $\left(10^{-9}-10^{-7} \mathrm{M}\right)$ relaxed the assay ring concentration-dependently. After treatment of donor vessels with LNAG $\left(10^{-4} \mathrm{M}\right)$ for $30 \mathrm{~min}$, neither of the relaxations was observed (Fig. 6B). In contrast, treatment of donor vessels with PMA $\left(10^{-7} \mathrm{M}\right)$ for $30 \mathrm{~min}$ showed no significant effects on basal and bradykinininduced relaxations (Fig. 6C). In addition, treatment of both donor and assay vessels with PMA $\left(10^{-7} \mathrm{M}\right)$ for 30 min also showed no significant effects on basal and bradykinin-induced relaxations (data not shown). Results of the experiments are quantitatively summarized in Fig. 7. LNAG $\left(10^{-4} \mathrm{M}\right)$ almost completely prevented both basal and bradykinin-induced release of EDRFs from donor vessels. However, PMA $\left(10^{-7} \mathrm{M}\right)$ showed no significant effect on basal and bradykinin-induced release from donor vessels. $\mathrm{EC}_{50}$ values for bradykinin were $(1.60 \pm 0.45) \times 10^{-9} \mathrm{M}$ in the control and $(4.12 \pm 1.31)$ $\times 10^{-9} \mathrm{M}$ in the PMA-treated preparation. There was no
(A)

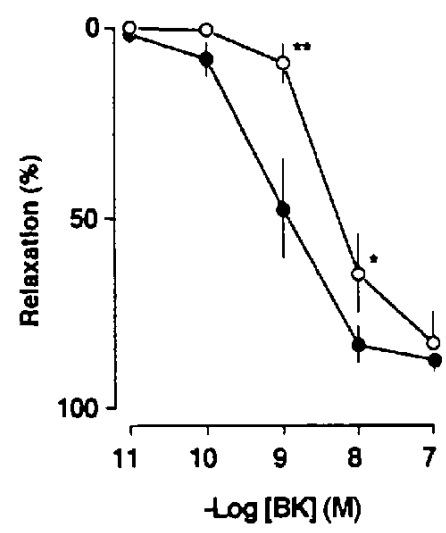

(B)

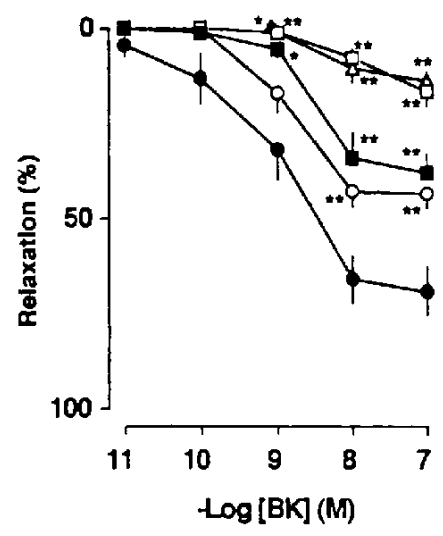

(C)

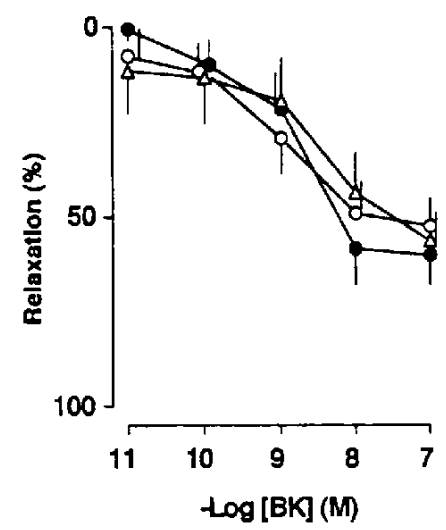

Fig. 5. Effects of phorbol 12-myristate-13-acetate (PMA) and 4-alpha-porbol 12,13-didecanoate (4 $\alpha$-PDD) on bradykinin (BK)-induced endothelium-dependent relaxation in bovine coronary arteries. Experiments were performed in the absence of L-nitro-arginine (LNAG) (A) and in the presence of LNAG $\left(10^{-4} \mathrm{M}\right)\left(\mathrm{B}\right.$ and C). In (A),, control; $\bigcirc$, PMA (10 $\left.{ }^{-6} \mathrm{M}\right)$. In (B), O, control; $\bigcirc$, PMA $\left(10^{-8} \mathrm{M}\right)$; $\square$, PMA $\left(3 \times 10^{-8} \mathrm{M}\right) ; \square$, PMA $\left(10^{-7} \mathrm{M}\right) ; \triangle$, PMA $\left(10^{-6} \mathrm{M}\right)$. In (C),, control; $\triangle, 4 \alpha-\mathrm{PDD}$ $\left(10^{-7} \mathrm{M}\right) ; \square, 4 \alpha$-PDD $\left(10^{-6} \mathrm{M}\right)$. Coronary rings were contracted with prostaglandin $\mathrm{F}_{2 \alpha}\left(3 \times 10^{-6} \mathrm{M}\right)$; the absolute contractions in controls (A), PMA $\left(10^{-6} \mathrm{M}\right)(\mathrm{A})$-treated rings, controls (B and C), PMA $\left(10^{-6} \mathrm{M}\right)(\mathrm{B})$ - and $4 \alpha-\mathrm{PDD}\left(10^{-6} \mathrm{M}\right)(\mathrm{C})$-treated rings were $40.0 \pm 2.9 \mathrm{mN}, 46.5 \pm 4.7 \mathrm{mN}, 48.1 \pm 2.6 \mathrm{mN}, 48.8 \pm 4.6 \mathrm{mN}$, and $46.6 \pm 3.9 \mathrm{mN}$, respectively. Relaxations induced by papaverine $\left(10^{-4} \mathrm{M}\right)$ were taken as $100 \%$. Each point represents the mean \pm S.E.M. of five to eight muscle strips from different animals. In the absence of LNAG (A), PMA $\left(10^{6} \mathrm{M}\right)$ significantly $\left({ }^{*} \mathrm{P}<0.05,{ }^{* *} \mathrm{P}<0.01\right)$ inhibited BK-induced relaxation. In the presence of LNAG (B), PMA $\left(10^{-8}-10^{-6} \mathrm{M}\right)$ significantly $\left({ }^{*} \mathrm{P}<0.05,{ }^{* *} \mathrm{P}<0.01\right)$ inhibited BK-induced relaxation, concentration-dependently. 


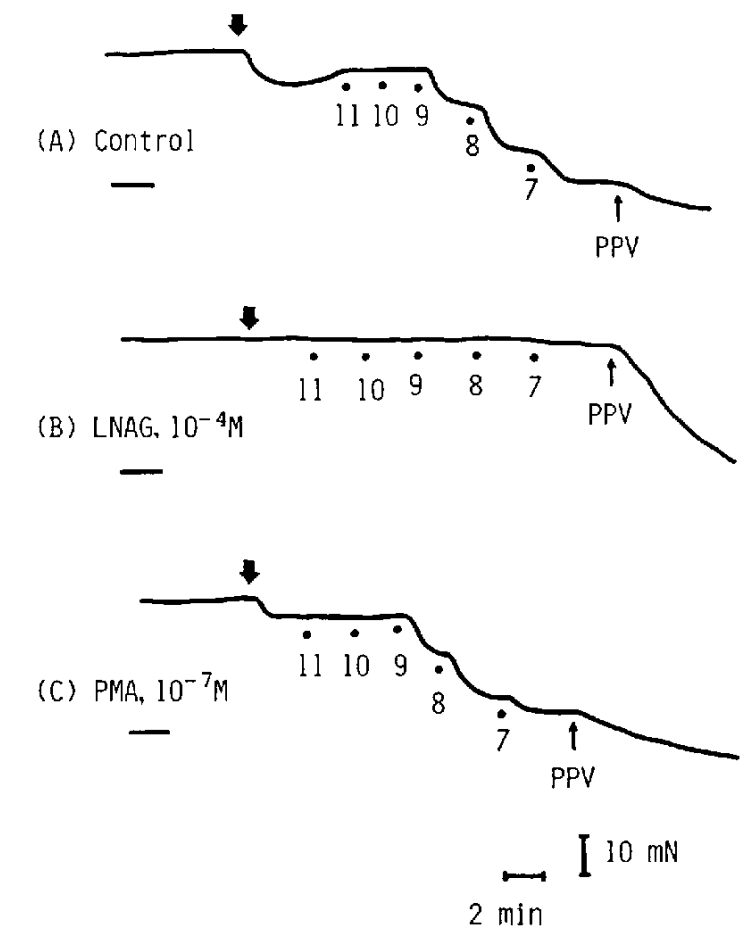

Fig. 6. Representative illustrations showing the effects of L-nitroarginine (LNAG) $\left(10^{4} \mathrm{M}\right)$ and/or phorbol 12-myristate-13-acetate (PMA) $\left(10^{-7} \mathrm{M}\right)$ on the release of endothelium-derived relaxing factors (EDRFs). (A) Relaxation of a bovine coronary artery (a denuded bioassay ring) in response to basal and bradykinin (BK)-induced release of EDRFs from the bovine coronary segments with endothelium (donor vessels). (B) Following exposure of donor vessels to LNAG $\left(10^{-4} \mathrm{M}\right)$ for $30 \mathrm{~min}$, both basal and BK-induced relaxation of the assay ring was abolished. (C) Treatment of donor vessels with PMA $\left(10^{-7} \mathrm{M}\right)$ for $30 \mathrm{~min}$ affected neither the basal nor BKinduced relaxations of the assay ring. BK was added to the organ chamber at the indicated points; numbers indicate the cumulative concentration $(-\log \mathrm{M})$ of $\mathrm{BK}$, and horizontal lines represent the level before the addition of prostaglandin $\mathrm{F}_{2 \alpha}\left(3 \times 10^{-6} \mathrm{M}\right)$. $\downarrow$, transfer of donor vessels to the assay chamber; PPV, papaverine $\left(10^{-4} \mathrm{M}\right)$.

significant difference between these two values. The maximal bradykinin-induced relaxation was $62.4 \pm 5.9 \%$ in the control and $59.9 \pm 4.8 \%$ in the PMA-treated preparation. There was no significant difference between these two values. However, the maximal relaxation in the preparation treated with LNAG was only $9.2 \pm 5.9 \%$, which was significantly different from the other values.

Inhibitory effects of LNAG on basal and bradykinin-induced relaxations were almost reversed by treatment with L-arginine $\left(9 \times 10^{-3} \mathrm{M}\right)$, but not with D-arginine $\left(9 \times 10^{-3} \mathrm{M}\right)$ (Fig. 8). Treatment of the assay vessel with oxyhemoglobin $\left(10^{-5} \mathrm{M}\right)$ or methylene blue $\left(10^{-5} \mathrm{M}\right)$ completely abolished both basal and bradykinin $\left(10^{-10}-10^{-7} \mathrm{M}\right)$ induced relaxations $(n=5)$.

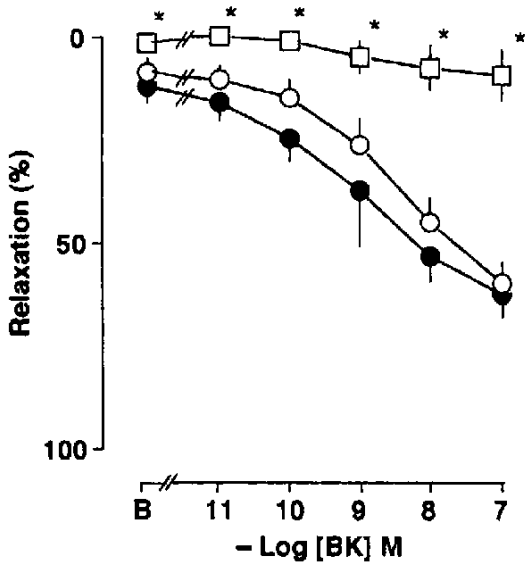

Fig. 7. Effects of L-nitro-arginine (LNAG) $\left(10^{-4} \mathrm{M}\right)$ and/or phorbol 12-myristate-13-acetate (PMA) $\left(10^{-7} \mathrm{M}\right)$ on the release of endothelium-derived relaxing factors from donor vessels. Donor vessels with endothelium were treated with $\operatorname{LNAG}\left(10^{-4} \mathrm{M}\right)(\square)$ or with PMA $\left(10^{-7} \mathrm{M}\right)(\bigcirc)$ for $30 \mathrm{~min}$, and then basal (B) and bradykinin (BK)-induced relaxation were estimated. Relaxations induced by papaverine $\left(10^{-4} \mathrm{M}\right)$ were taken as $100 \%$. Each point represents the mean \pm S.E.M. of seven experiments from different animals. *: LNAG significantly $(P<0.05)$ inhibited the basal and BK-induced relaxations. Control.

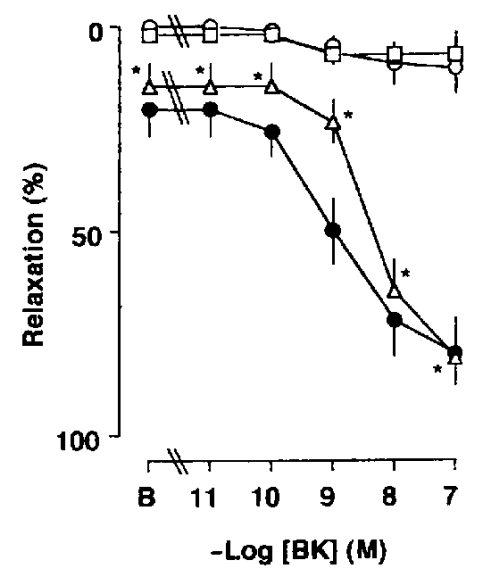

Fig. 8. Antagonizing effects of $L$-arginine and $D$-arginine on the inhibitory effect of $\mathbf{L}$-nitro-arginine (LNAG). Donor vessels with endothelium were treated with $\operatorname{LNAG}\left(10^{-4} \mathrm{M}\right)$ only $(O)$ and together with L-arginine $(\triangle)$ or $D$-arginine $\left(9 \times 10^{-3} \mathrm{M}\right)(\square)$ for $30 \mathrm{~min}$, and then basal (B) and bradykinin (BK)-induced relaxations were estimated. Relaxations induced by papaverine $\left(10^{-4} \mathrm{M}\right)$ were taken as $100 \%$. Each point represents the mean \pm S.E.M. of six experiments from different animals. *: L-arginine significantly $(\mathrm{P}<0.05)$ antagonized the inhibitory effect of LNAG. : Control.

\section{DISCUSSION}

The present experiments showed that in isolated bovine coronary arteries, bradykinin evokes LNAG-insensitive, endothelium-dependent relaxation. This relaxation was in- 
hibited by PMA. These results suggest that in bovine coronary arteries, an EDRF(s) other than nitric oxide may participate in the relaxation caused by bradykinin. In isolated porcine coronary arteries, it has been shown that an $\operatorname{EDRF}(\mathrm{s})$, which is different from nitric oxide, may participate in the bradykinin-induced endothelium-dependent relaxation $(4,7,8,15)$. However, studies on arterial rings mounted in the organ chamber do not allow one to determine whether LNAG-insensitive and PMA-sensitive endothelium-dependent relaxation is mediated by a diffusible relaxing factor(s).

In an attempt to detect the release of EDRFs, experiments were designed in a sandwich system (Fig. 1). Our most important finding is that treatment of donor vessels with LNAG almost completely inhibited the release of relaxing mediator(s) detectable in the sandwich system (Fig. 6B). In contrast, PMA showed no significant effect on the release of relaxing mediator(s) detectable in this sandwich system (Fig. 6C). These results suggest that bradykinin-induced endothelium-dependent relaxation may involve both the release of a diffusible factor (nitric oxide) and a non-diffusible factor(s) or an extremely labile diffusible factor(s). There are two other possible explanations for the bradykinin-induced, LNAG-insensitive, endotheliumdependent relaxation. One is that the relaxation may be mediated by the spread of endothelial cell membrane hyperpolarization to vascular smooth muscle cells as reported in canine and porcine coronary arteries $(6,16)$. The possibility is that the relaxation may be mediated by the release of $\operatorname{EDHF}(7,17,18)$. The present results obtained from bovine coronary arteries are similar to those reported in porcine coronary arteries showing that bradykinin-induced LNAG-insensitive endothelium-dependent relaxation is not mediated by bioassayable relaxing substances (19).

It has been reported that activation of protein kinase $\mathrm{C}$ by phorbol esters inhibits the endothelium-dependent relaxation evoked by acetylcholine and other agonists (11, 20-22). In contrast to acetylcholine, endothelium-dependent relaxations evoked by bradykinin or by the calcium ionophore A23187 were little affected by phorbol myristate acetate $(12,23)$. Similar results were obtained in the present study (Figs. 3C and 5A). However, PMA almost completely abolished the bradykinin-induced relaxation in the presence of LNAG (Fig. 3D). These results support the suggestion that at least two EDRFs might contribute to the bradykinin-induced relaxation in bovine coronary arteries: nitric oxide and a non-diffusible or an extremely labile factor. These observations also indicate that nitric oxide is continuously synthesized and released from the endothelium (Fig. 6A), and this basal release of EDRF was inhibited by LNAG (Fig. 6B). PMA inhibited neither the basal release (Fig. 6C) nor the brady- kinin-induced relaxation (Figs. 6C and 7). These results suggest that PMA might selectively inhibit the production or release of an EDRF different from nitric oxide.

The inhibitory effect of PMA may result from activation of protein kinase $C$ in endothelial cells (24). In this study, $4 \alpha-\mathrm{PDD}$, which does not activate protein kinase $\mathrm{C}$, did not affect the LNAG-insensitive, endothelium-dependent relaxation evoked by bradykinin. PMA did not influence the ability of the vascular smooth muscle to relax in response to nitroprusside which induced vascular smooth muscle relaxation by stimulation of soluble guanylate cyclase (25). Therefore, the observed inhibitory effect of PMA on LNAG-insensitive, endothelium-dependent relaxation may reflect an interruption of the signal transduction mechanisms in the endothelial cells. It has been reported that in canine coronary arteries, PMA (12) or phorbol 12,13-dibutyrate (13) evokes the endothelium-dependent contraction. However, PMA did not affect the basal tension of bovine coronary arteries with intact endothelium in this study. While the exact cause of species differences is unknown, it is tentatively speculated that a difference in the ratio of nitric oxide and non-nitric oxide factor(s) participating in endothelium-dependent mechanisms might contribute to it.

On the other hand, it has been reported that phorbol esters stimulate endothelial cells to release superoxide anions (26), which may cause nonspecific depression of endothelium-dependent relaxations by inhibiting the activity of endothelium-derived nitric oxide $(27,28)$. In the present experiments, the presence of PMA in the sandwich bioassay system did not influence the bradykinininduced relaxations, suggesting that the inhibitory effect of PMA on LNAG-insensitive relaxation does not result from an increased release of superoxide. The results of the present study suggest that an increased activation of protein kinase $\mathrm{C}$ could be responsible for loss of bradykinin-induced LNAG-insensitive, endothelium-dependent relaxations of bovine coronary arteries.

It is concluded that in bovine coronary arteries, bradykinin releases nitric oxide and other endothelium-derived relaxing factor(s) which is an extremely labile substance(s) or a non-diffusible factor(s). These results together with evidence for the existence of endothelium-derived contractile and relaxing endothelins $(29,30)$ indicate the complex influence of the endothelium on vascular smooth muscle tone. Further studies on EDRFs other than nitric oxide are underway.

\section{REFERENCES}

1 Furchgott, R.F.: Endothelium-dependent relaxation in systemic arteries. In Relaxing and Contracting Factors, Edited by Vanhoutte, P.M., pp. 1-26, The Humana Press Inc., Clifton 
(1988)

2 Palmer, R.M.J., Ferrige, A.G. and Moncada, S.: Nitric oxide release accounts for the biological activity of derived relaxing factor. Nature 327, 524-526 (1987)

3 Rubanyi, G.M., Johns, A., Wilcox, D., Bates, F.N. and Harrison, D.: Evidence that a $S$-nitrosothiol, but not nitric oxide, may be identical with endothelium-derived relaxing factor. J. Cardiovasc. Pharmacol. 17, Supp. 3, S41-S45 (1991)

4 Richard, V., Tanner, F.C., Tschudi, M. and Lüscher, T.F.: Different activation of $\mathrm{L}$-arginine pathway by bradykinin, serotonin, and clonidine in coronary arteries. Am. J. Physiol. 259, H1433-H1439 (1990)

5 Myers, P.R., Guerra, R., Jr. and Harrison, D.G.: Release of multiple endothelium-derived relaxing factors from porcine coronary arteries. J. Cardiovasc. Pharmacol. 20, 392-400 (1992)

6 Pacicca, C., Von der Weid, P.-Y. and Bény, J.-L.: Effect of nitro-L-arginine on endothelium-dependent hyperpolarizations and relaxations of pig coronary arteries. J. Physiol. (Lond.) 457, 247-256 (1992)

7 Nagao, T. and Vanhoutte, P.M.: Hyperpolarization as a mechanism for endothelium-dependent relaxations in the porcine coronary artery. J. Physiol. (Lond.) 445, 355- 367 (1992)

8 Cowan, C.L. and Cohen, R.A.: Two mechanisms mediate relaxation by bradykinin of pig coronary artery: NO-dependent and -independent responses. Am. J. Physiol. 261, H830-H835 (1991)

9 Nagao, T. and Vanhoutte, P.M.: Characterization of endothelium-dependent relaxations resistant to nitro-L-arginine in the porcine coronary artery. Br. J. Pharmacol. 107, 1102-1107 (1992)

10 Matsumoto, T., Kinoshita, M. and Toda, N.: Mechanisms of endothelium-dependent responses to vasoactive agents in isolated porcine coronary arteries. J. Cardiovasc. Pharmacol. 22, 228- 234 (1993)

11 Obi, T. and Nishio, A.: L-Nitro-arginine-sensitive and L-nitroarginine-resistant endothelium-dependent relaxation in cattle coronary artery in vitro. Japan. J. Pharmacol. 61, Supp. I, 232P (1993)

12 Flavahan, N.A., Shimokawa, H. and Vanhoutte, P.M.: Inhibition of endothelium-dependent relaxations by phorbol myristate acetate in canine coronary arteries: Role of a pertussis toxin-sensitive G-protein. J. Pharmacol. Exp. Ther. 256, 50-55 (1991)

13 Rubanyi, G.M., Desiderio, D., Luisi, A., Johns, A. and Sybertz, E.J.: Phorbol dibutyrate inhibits release and action of endothelium-derived relaxing factor(s) in canine blood vessels. J. Pharmacol. Exp. Ther. 249, 858-863 (1989)

14 Rosolowsky, M. and Campbell, W.B.: Role of $\mathrm{PGI}_{2}$ and epoxyeicosatrienoic acids in relaxation of bovine coronary arteries to arachidonic acid. Am. J. Physiol. 264, H327-H335 (1993)

15 Tschudi, M., Richard, V., Bühler, F.R. and Lüscher, T.F.: Importance of endothelium-derived nitric oxide in porcine coronary resistance arteries. Am. J. Physiol. 260, H13-H20 (1991)

16 Brunet, P.C. and Beny, J.-L.: Substance P and bradykinin hyperpolarize pig coronary artery endothelial cells in primary culture. Blood Vessels 26, 228-234 (1989)

17 Chen, G., Suzuki,H. and Weston, A.H.: Acetylcholine releases endothelium-derived hyperpolarizing factor and EDRF from rat blood vessels. Br. J. Pharmacol. 95, 1165-1174 (1988)

18 Nagao, T., Illiano, S. and Vanhoutte, P.M.: Calmodulin antagonists inhibit endothelium-dependent hyperpolarization in the canine coronary artery. Br. J. Pharmacol. 107, 382-386 (1992)

19 Kauser, K. and Rubanyi, G.M.: Bradykinin-induced, $N^{\prime \prime}$-nitro$\mathrm{L}$-arginine-insensitive endothelium-dependent relaxation of porcine coronary arteries is not mediated by bioassayable relaxing substances. J. Cardiovasc. Pharmacol. 20, Supp. 12, S101S104 (1992)

20 Weinheimer, G., Wagner, B. and Osswald, H.: Interference of phorbolesters with endothelium-dependent vascular smooth muscle relaxation. Eur. J. Pharmacol. 130, 319-322 (1986)

21 Smith, J.A. and Lang, D.: Release of endothelium-derived relaxing factor from pig cultured aortic endothelial cells, as assessed by changes in endothelial cell cyclic GMP content, is inhibited by a phorbol ester. Br. J. Pharmacol. 99, 565-571 (1990)

22 Lewis, M.J. and Henderson, A.H.: A phorbol ester inhibits the release of endothelium-derived relaxing factor. Eur. J. Pharmacol. 137, 167-171 (1987)

23 Cherry, P.D. and Gillis, C.N.: Antagonism of acetylcholinemediated relaxation of rabbit pulmonary arteries by phorbol myristate acetate. J. Pharmacol. Exp. Ther. 247, 542-546 (1989)

24 Castagna, M., Takai, Y., Kaibuchi, K., Sano, K., Kikkawa, U. and Nishizuka, Y.: Direct activation of calcium-activated, phospholipid-dependent protein kinase by tumor-promoting phorbol esters. J. Biol. Chem. 257, 7847-7851 (1982)

25 Rapoport, R.M. and Murad, F.: Endothelium-dependent and nitrovasodilator-induced relaxation of vascular smooth muscle: Role of cyclic GMP. J. Cyclic Nucleotide Protein Phosphor. Res. 9, 281-286 (1983)

26 Matsubara, T. and Ziff, M.: Superoxide anion release by human endothelial cells: Synergism between a phorbol ester and a calcium ionophore. J. Cell. Physiol. 127, 207-210 (1986)

27 Rubanyi, G.M. and Vanhoutte, P.M.: Superoxide anions and hyperoxia inactivate endothelium-derived relaxing factor. Am. J. Physiol. 250, H822-H827 (1986)

28 Gryglewski, R.J., Palmer, R.M.J. and Moncada, S.: Superoxide anion is involved in the breakdown of endothelium-de rived vascular relaxing factor. Nature 320, 454-456 (1986)

29 Yanagisawa, M., Kurihara, H., Kimura, S., Tanabe, Y., Kobayashi, M., Mitsui, Y., Yazaki, Y., Goto, K. and Masaki, $T$.: A novel potent vasoconstrictor peptide produced by vascular endothelial cells. Nature 332, $411-415$ (1988)

30 Moritoki, H., Miyano, H., Takeuchi, S., Yamaguchi, M., Hisayama, T. and Kondoh, W.: Endothelin-3-induced relaxation of rat thoracic aorta: a role for nitric oxide formation. $\mathrm{Br}$. J. Pharmacol. 108, 1125-1130 (1993) 